\title{
Non-intubated thoracic epidural anesthesia for modified radical mastectomy as an alternative to general anaesthesia
}

Gönül Sağıroğlu ${ }^{1}$, Atakan Sezer ${ }^{2}$, Ethem Cakcak ${ }^{2}$, Elif Çopuroğlư ${ }^{1}$, Tamer Sagiroglu², S. Hekimoglu ${ }^{2}$

1. Assoc Professor of Anesthesiology, Department of Anesthesiology, Trakya University, Faculty of Medicine, Edirne, Turkey.

2. Assoc Professor of Department of General Surgery, Trakya University, Faculty of Medicine, Edirne, Turkey

Study performed at Trakya University Faculty of Medicine, Turkey.

Financial support: None.

Conflict of interest: G. Sagiroglu, A. Sezer, E. Cakcak, E. Copuroglu, T. Sagiroglu and S. Hekimoglu declare that they have no competing interests..

Correspondence address: Trakya University Faculty of Medicine Department of Anesthesiology Edirne, 22030, Turkey E-mail: gonulsagiroglu45@gmail.com

Submitted: February 07, 2018. Accepted, after review: March 20, 2018.

\section{ABSTRACT}

Purpose: We provide the application of modified radial mastectomy in perioperative treatment under awake thoracic epidural block in breast cancer operations. Methods: Twelve women who underwent modified radical mastectomy in elective breast cancer surgery were included in the study. All patients were treated without tracheal intubation using thoracic epidural anesthesia and sedation. The epidural catheter was placed in the T 4-5 level and the mixture of $0.5 \%$ bupivacaine and fentanyl was gradually administered with careful haemodynamic monitoring. Target-controlled propofol infusion was used. Pain intensity was evaluated by using a $10 \mathrm{~cm}$ VAS, where zero represented no pain and $10 \mathrm{~cm}$ represented worst possible pain. The primary endpoint was pain. A VAS score of $4 \mathrm{~cm}$ or less was considered to be an acceptable level of pain. The sedation situation was focused and calm in Wilson 2 level and in cooperation with sedation. Preoperative comorbidity and perioperative therapy were recorded. Results: We observed 4 hypotensive patients treated by increasing intravenous fluid infusion rate and initiating dopamine infusion. One patient had bradycardia, one patient had nausea and three patients had vomiting. There were no respiratory complications or pruritus. The mean duration of hospitalization is 5 days postoperatively. The patient had no intraoperative or postoperative complications. Conclusion: Epidural block in axillary lymph node dissection and oncologic mastectomy may be considered as a safe anesthetic option.

Key words: Thoracic epidural anesthesia. Modified radical mastectomy. 


\section{OBJETIVO}

Objetivo: Fornecer a aplicação bem sucedida de mastectomia radial modificada em tratamento perioperatório sob anestesia peridural torácica acordada em operações de câncer mama. Métodos: Doze mulheres submetidas a mastectomia radical modificada em cirurgia eletiva de câncer de mama foram incluídas no estudo. Todas as pacientes foram tratados sem intubação traqueal com anestesia peridural torácica e sedação. 0 cateter epidural foi colocado no nível T 4-5 e a mistura de bupivacaína a 0,5\% e fentanil foi gradualmente administrado com monitorização hemodinâmica cuidadosa. A infusão de propofol controlada por alvo foi utilizada. A intensidade da dor foi avaliada com $10 \mathrm{~cm}$ VAS; zero dor e $10 \mathrm{~cm}$ dor pior. O desfecho primário foi a dor. A situação de sedação foi focada e calma no nível Wilson 2 e em cooperação com sedação. Comorbidade pré-operatória e terapia perioperatória foram registradas. Resultados: Observamos 4 pacientes hipotensas tratadas pelo aumento da infusão de fluidos intravenosos e inciao da infusão de dopamina. Uma paciente apresentou bradicardia, uma paciente apresentou náuseas e três pacientes apresentaram vômitos. Não houve complicações respiratórias ou prurido. A duração média da hospitalização foi de 5 dias após a cirurgia. As pacientes não apresentaram complicações intraoperatórias ou pós-operatórias. Conclusão: o bloqueio peridural dissecção de linfonodos axilares e mastectomia oncológica pode ser considerado um opção anestésica.

Descritores: Anestesia peridural torácica. Mastectomia radical modificada.

\section{INTRODUCTION}

Modified radical mastectomy (MRM) is usually performed under general anesthesia (GA). However, GA includes inadequate postoperative pain control and routine use of parenteral opioids aggravate postoperative sedation, high incidence of nausea and vomiting, impaired oxygenation and depressed ventilation ${ }^{1}$.

There is growing interest to do this surgery under regional anaesthesia. Regional anesthesia techniques like high thoracic epidural anesthesia (TEA), cervical epidural anesthesia and paravertebral block have been applied successfully in mastectomy operations ${ }^{2}$. TEA advantages are less intraoperative blood loss and surgical stress response and earlier start of feeding compared to patients with general anesthesia. Furthermore, this application positively affects the early mobilization and 
Non-intubated thoracic epidural anesthesia for modified radical mastectomy as an alternative to general anaesthesia

Sağıroğlu $G$, et al

hospital stay ${ }^{2,3}$. Successful use of high TEA avoids problems of difficult tracheal intubation, stress of anesthesia and surgery and hemodynamic changes associated with tracheal intubation. Stress associated with anesthesia and surgery results in increased catecholamine levels, increased left ventricular afterload, heart rate, and cardiac complications. TEA reduces adverse perioperative cardiac and sympathetic activity, perioperative complications and mortality ${ }^{4}$.

This study was designed to determine the efficacy and safety of TEA as an anesthetic technique for mastectomy and axillary dissection.

\section{METHODS}

Prior to anesthesia, doctors visited each patient to explain the anesthesia process and method; informed consent was obtained from all enrolled patients, who signed "Consent to Thoracic Epidural Anesthesia with Nontracheal Intubation". A total of twelve women scheduled for MRM for elective breast cancer surgery were recruited in this study. The age range was between 33 and 62 including American Society of Anesthesiologists physical status I to III.

Exclusion criterias include; puncture in the skin, infection, bacteremia, hypovolemia, blood disorders, or abnormal clotting mechanism, prior lumbar spine surgery or vertebral column deformity, ASA physical status > III, chronic opioid or sedative drug use, hepatic, or renal failure, alcohol abuse or drug abuse, obesity (> $130 \%$ of ideal body weight) and a history of allergy to local anesthetics, neurological impairment causing inability to understand consent form or pain measurement.

Demographic data, age, height, weight, body mass index and surgical procedures (partial or total mastectomy with or without axillary lymph node dissection or for plastic surgery) were recorded. Comorbidities were defined and graded according to the Charlson comorbidity index ${ }^{5}$. Nineteen conditions were defined as significantly influencing survival in the study population and were given a weighted score based on the relative mortality risk. The sum of the weighted scores of all the comorbid conditions in cancer patients was then scaled to establish the Charlson 
Non-intubated thoracic epidural anesthesia for modified radical mastectomy as an alternative to general anaesthesia

Sağıroğlu $G$, et al

comorbidity index. The weights range from 1 to 6 ( 0 if the comorbidity is absent) and four Charlson comorbidity index classes were defined as $0,1-2,3-4$ and $\geq 5^{5}$.

No premedication was done in patients. After securing intravenous access, the patient was preloaded with $10 \mathrm{~mL} / \mathrm{kg}$ of lactated Ringer's solution slowly over 30 minutes. Patients were monitored with twelve-lead ECG (leads II and $V_{5}$ ) for heart rate (HR) and ST segment changes, non-invasive blood pressure, arterial oxygen saturation by pulse oxymetry $\left(\mathrm{SpO}_{2}\right)$ and sedation score from one to five scales. We recorded the first measurements as the initial value.

Then, an epidural catheter was placed at $\mathrm{T}_{4-5}$ space under aseptic conditions with a 18-gauge Tuohy needle using the midline approach. The epidural space was identified with the loss of resistance to saline technique. The epidural catheter was advanced cephaled for $3-4 \mathrm{~cm}$ in the epidural space to position the tip approximately. A test dose of $2 \mathrm{~mL}$ of $2 \%$ lidocaine was given to rule out subarachnoid or intravascular placement of the catheter. The misplacement of thoracic epidural was tested after insertion of the catheter by aspiration of blood or colored fluids to check for hemorrhage, insertion of the catheter into other cavities such as pleura or intravertebral foramen. This action was followed by a total of $7 \mathrm{~mL}$ of $0.5 \%$ bupivacaine with $1 \mu \mathrm{g} / \mathrm{mL}$ fentanyl given gradually via careful hemodynamic monitoring. Sensory blockade was assessed by pin prick every 5 min for up to $25 \mathrm{~min}$ after epidural injection. Loss of sensation from the $T_{2}$ and $T_{8}$ dermatomes was achieved. The surgery was started only when there was no response by the patient to a pinprick in the surgical field. During operation analgesia was administered by $10 \mathrm{mg}$ bolus doses of epidural bupivacaine diluted in $5 \mathrm{~mL}$ of saline when the patient reported a visual analogue scale (VAS) scores of 4 or more. If the VAS score less than 4 could not be achieved with single dose a second dose was provided. Sensory blockade was assessed by pin prick every $5 \mathrm{~min}$ for up to $30 \mathrm{~min}$ after epidural injection. Targetcontrolled infusion of propofol was used. Sedation state was kept at cooperated, oriented and tranquilized at Wilson 2 level and the sedation was stopped during wound closure ${ }^{6}$. 
Non-intubated thoracic epidural anesthesia for modified radical mastectomy as an alternative to general anaesthesia

Sağıroğlu $G$, et al

During anesthesia, if $\mathrm{SpO}_{2}$ declines to $<90 \%$, assisted ventilation via nasal is required to improve oxygenation (2-4 L/min). If nasal assisted ventilation does not improve the condition, the procedure should be shifted to endotracheal intubation.

Mean arterial blood pressure (MAP), $\mathrm{HR}$ and $\mathrm{SpO}_{2}$ were measured in the perioperative period. Patients whose arterial blood pressure values are normal but the $\mathrm{SpO}_{2}$ value is $90 \%$ or less were regarded as hypoxic. We reduced the propofol infusion dosage $1 \mathrm{mg} / \mathrm{kg} / \mathrm{h}$ when MAP was $20 \%$ of the baseline value or lower or the respiratory rate dropped below 8 breath/min and increased infusion of propofol $1 \mathrm{mg} / \mathrm{kg} / \mathrm{h}$ when the MAP was $20 \%$ of the baseline value or greater. We terminated infusion of propofol for about 5 minutes before the end of surgery. The need for additional analgesic medication, development of dyspnea, and tolerance of regional anesthesia were recorded. The epidural catheter was removed at the end of the day of surgery.

Hypotensive episodes (decrease in MAP below $60 \mathrm{mmHg}$ ) were treated with bolus of isotonic fluid and dopamine infusion. Bradycardia (decrease in HR below 45/bpm) were administered with intravenous atropine at a dose of $0.01 \mathrm{mg} / \mathrm{kg}$. Presence of nausea and vomiting were noted till 24 hours and was scored described by Callesen et al: 1=no nausea, no vomiting, 2=light nausea, one episode of vomiting, $3=$ mild nausea, two episode of vomiting, 4=severe nausea, three or more episodes of vomiting ${ }^{7}$. Nausea and vomiting were treated with intermittent bolus injection metoclopramide at a dose of $10 \mathrm{mg}$ intravenously. All drug administrations were recorded.

\section{Endpoints}

Pain intensity was evaluated by using a $10 \mathrm{~cm}$ VAS, where zero represented no pain and $10 \mathrm{~cm}$ represented worst possible pain. The primary endpoint was pain. $A$ VAS score of $4 \mathrm{~cm}$ or less was considered to be an acceptable level of pain. Intravenous lornoxicam $8 \mathrm{mg}$ was given to patients with a VAS value was 4 or greater at postoperative first 24 hours and total lornoxicam requirements were recorded. Sedation level was assessed at 15 minutes interval using the sedation score described by Wilson et al as: 1=fully awake and oriented, $2=$ drowsy, $3=e y e s$ closed but arousable 
Non-intubated thoracic epidural anesthesia for modified radical mastectomy as an alternative to general anaesthesia

Sağıroğlu G, et al

to command, 4=eyes closed but arousable to mild physical stimulation (earlobe tug), $5=e y e s$ closed but unarousable to mild physical stimulation ${ }^{6}$.

Secondary end points we assessed the complications. Secondary endpoints we assessed the complications, such as hypotension, bradycardia, nausea and vomiting, respiratory depression, allergy for 24 hours.

\section{Statistical Analysis}

We used SPSS (Statistical Package for Social Sciences) v.13.0 for Windows for statistical analysis of the obtained data. The statistical data were expressed as the mean \pm standard deviation or median (range) and categorical variables are reported as percentages. Other variables were assessed via non-parametric tests. Probability values of, 0.05 were considered to be statistically significant.

\section{RESULTS}

All of the patients were operated under elective conditions. All 12 patients completed the study. The comparison of demographic data and perioperative clinical characteristics were summarized in Table 1.

Table 1 - Clinical characteristics of patients.

\begin{tabular}{lcc}
\hline \multicolumn{1}{c}{ Population } & Mean \pm SS & Quartile range \\
\hline Age, years & $50.25 \pm 10.41$ & $33-62$ \\
Height, $\mathrm{cm}$ & $159.91 \pm 3.94$ & $155-168$ \\
Weight, $\mathrm{kg}$ & $78.08 \pm 12.84$ & $56-100$ \\
Body mass index, $\mathrm{kg} / \mathrm{m}^{2}$ & $30.65 \pm 5.43$ & $22-39$ \\
ASA score, I/II & $5 / 7$ & \\
Unable to place the catheter & None & \\
Conversion to intubation & None & \\
\hline Charlson comorbidity index & & \\
0 & $9(75)$ & \\
1 & $2(16.7)$ & \\
$\geq 2$ & $1(8.3)$ & \\
\hline Surgical side & & \\
Right & $8(66.7)$ & \\
Left & $4(33.3)$ & \\
\hline ASA:American &
\end{tabular}

ASA: American society of anesthesiologists

Data listed as mean \pm standard deviation; $n(\%)$, number (percent) 
Non-intubated thoracic epidural anesthesia for modified radical mastectomy as an alternative to general anaesthesia

Sağıroğlu $G$, et al

When we compare the hemodynamic parameters intraoperatively with basal values: decreasing of the Systolic and diastolic arterial pressure values at 10, 15, 30, 45 minutes, decreasing of the MAP values at 3, 10, 15, 30 minutes and decreasing of the HR values at 10, 15, 30 minutes are found statistically meaningfull (Table 2).

Table 2 - Changes of hemodynamic parameters compared to the basal values according to the time intraoperatively.

\begin{tabular}{|c|c|c|c|c|c|c|c|c|}
\hline \multirow{2}{*}{$\begin{array}{l}\text { Time } \\
\text { (min) }\end{array}$} & \multicolumn{2}{|l|}{ SAP } & \multicolumn{2}{|l|}{ DAP } & \multicolumn{2}{|l|}{ MAP } & \multicolumn{2}{|l|}{ HR } \\
\hline & Mean $\pm S S$ & p & Mean $\pm S S$ & $\mathbf{p}$ & Mean $\pm S S$ & $\mathbf{p}$ & Mean $\pm S S$ & $\mathbf{p}$ \\
\hline Basal & $146.67 \pm 17.27$ & & $83.17 \pm 11.78$ & & $104.33 \pm 12.08$ & & $81.33 \pm 17.12$ & \\
\hline 5 & $135.33 \pm 27.88$ & 0.059 & $80.67 \pm 9.8$ & 0.61 & $98.89 \pm 14.59$ & $0.024 *$ & $77 \pm 12.8$ & 0.068 \\
\hline 10 & $129 \pm 29.98$ & $0.014^{*}$ & $73.5 \pm 18.89$ & $0.022 *$ & $92.11 \pm 21.41$ & $0.01 *$ & $73.92 \pm 15.53$ & $0.041^{*}$ \\
\hline 15 & $129 \pm 23.72$ & $0.005^{*}$ & $73.83 \pm 14.25$ & $0.009 *$ & $92.22 \pm 16.4$ & $0.003^{*}$ & $73.5 \pm 16.85$ & $0.012 *$ \\
\hline 30 & $132.42 \pm 19,91$ & $0.015^{*}$ & $75.25 \pm 11.5$ & $0.021 *$ & $94.31 \pm 12.03$ & $0.004^{*}$ & $74.42 \pm 13.06$ & $0.033^{*}$ \\
\hline 45 & $137.08 \pm 14.23$ & $0.033^{*}$ & $79 \pm 10.78$ & $0.037^{*}$ & $98.36 \pm 9.84$ & 0.088 & $74.83 \pm 13.76$ & 0.078 \\
\hline 60 & $141.08 \pm 12.06$ & 0.107 & $81.92 \pm 9.76$ & 0.465 & $101.64 \pm 8.12$ & 0.135 & $76.25 \pm 13.59$ & 0.11 \\
\hline 90 & $144.33 \pm 12.86$ & 0.25 & $80.33 \pm 7.08$ & 0.101 & $101.67 \pm 7.63$ & 0.108 & $75.92 \pm 13.87$ & 0.106 \\
\hline
\end{tabular}

SAP: Systolic arterial pressure

DAP: Diastolic arterial pressure

MAP: Mean arterial pressure

HR: Heart rate

Data listed as mean \pm standard deviation; ${ }^{*}$ Comparison to basal value in patients, $p<0.05$

When we analyse the intraoperative complications; hypotensive four patients are treated by increasing intravenous fluid infusion but we start dopamine infusion to two of these four patients who are still hypotensive despite of fluid infusion. Bradycardia is developed in one patient who is treated by one time $0.01 \mathrm{mg} / \mathrm{kg}$ atropine administration. Three patients who has nausea are treated by $10 \mathrm{mg}$ metoclopramide administration (Table 3). 
Non-intubated thoracic epidural anesthesia for modified radical mastectomy as an alternative to general anaesthesia

Sağıroğlu $G$, et al

Table 3 - Intraoperative period.

\begin{tabular}{lcc}
\hline \multicolumn{1}{c}{ Variable } & Mean \pm SS & Quartile range \\
\hline Total propofol consumption $(\mathrm{mL})$ & $89.17 \pm 90.9$ & $0-240$ \\
Fluid infusion $(\mathrm{mL})$ & $1566.67 \pm 365.15$ & $1000-2000$ \\
Bleeding $(\mathrm{mL})$ & $40 \pm 39.08$ & $10-100$ \\
Anesthesia duration $(\mathrm{min})$ & $82.08 \pm 37.02$ & $45-160$ \\
Surgical duration $(\mathrm{min})$ & $59.17 \pm 25.03$ & $30-100$ \\
Hospital stay (days) & $5.25 \pm 0.62$ & $4-6$ \\
\hline Complications & & \\
Hypotension & $4(33.3)$ & \\
Bradycardia & $1(8.3)$ & \\
Vomiting & $3(25)$ & \\
Nausea & $1(8.3)$ & \\
Respiratory complications & None & \\
Pruritus & None & \\
\hline
\end{tabular}

Data listed as mean \pm standard deviation; $\mathrm{N}(\%)$, number (percent)

Two patients who have VAS values higher than four postoperatively are treated by administration of lornoxicam $8 \mathrm{mg}$ intravenously. The mean length of hospitalization in the postoperative period is 5 days. Patient did not have any complication either intraoperatively or postoperatively. During follow-up patients are very satisfied, attitude was positive and have only slight discomfort in affected limb which can be treated by regular physiotherapy.

\section{DISCUSSION}

Curative or palliative cancer surgery often requires prolonged surgery of the thorax, abdomen, or some- times both. These surgical procedures can have a duration of several hours, are frequently associated with significant blood and temperature loss and potentially require the patient to have prolonged intubation of the tracheal and mechanical ventilation of the lungs, depending on the anesthetic technique. Moreover, patients may experience not only severe postoperative pain, but also profound disturbances of pulmonary, gastrointestinal and occasionally cardiac function. The use of an anesthetic technique, which will allow for optimal surgical conditions, reduced blood loss, provide for rapid recovery of the patient from the anesthetic, early extubation of the trachea and excellent postoperative analgesia, may have a significant 
Non-intubated thoracic epidural anesthesia for modified radical mastectomy as an alternative to general anaesthesia

Sağıroğlu $G$, et al

impact on the patients recovery from this major surgical insult. It is possible to have a fully awake and pain-free patient at the end of the surgery by using adequate doses of epidural local anesthetics intra-operatively and by decreasing the doses of opioid anesthetics, even after extensive surgical procedures of the thorax and abdomen lasting several hours.

The main results of a study which includes 60 patients is made by Doss and friends are that the patients in the TEA group had significantly shorter postanesthesia recovery, had significantly less nausea and vomiting, and experienced significantly less pain after surgery than patients in the GA group ${ }^{8}$.

Another study shows that, hypertension was more frequent in GA group (28.6\% vs. 0\%), while hypotension was more frequent in the TEA ( $80 \%$ vs. $57.1 \%)$, intra-operatively. Tachycardia was more frequent in GA group (46.6\% vs. 0\%), mean while bradycardia was more frequent in TEA (40\% vs. $17.1 \%)$. Postoperatively, the GA group had shorter post anesthetic care unit stay than TEA (230 mins vs. 267 mins), but TEA group had a shorter time of hospital stay compared to GA (58.1 hours vs. 67.7 hours). The incidence of postoperative nausea and vomitting were comparable among the two groups. Statistically there were no significant differences between the two groups in all of the above characteristics ${ }^{9}$.

Hiremath made a study with a type 2 diabetes mellitus patient who had MRM under TEA. Patients tolerated the procedure well without any perioperative complications with additional benefit of prolonged postoperative analgesia ${ }^{10}$.

Belzarena at all evaluated a comparative study between TEA and GA for the oncologic surgeries of the breasts. There was no difference for the duration of the surgery between two groups. They had to add complementary sedation anesthesia for the all patients of TEA group. While hypertension was more frequent in the GA group, hypotension was more frequent in the TEA group. Nausea and vomiting were more frequent in the GA group and analgesia was better in the TEA group. So the hospital stay duration was lower in the TEA group ${ }^{11}$.

A comparative study between GA and TEA for MRM patients was made by Yehh at all. They studied 64 patients. The results showed that TEA provided a more 
Non-intubated thoracic epidural anesthesia for modified radical mastectomy as an alternative to general anaesthesia

Sağıroğlu $G$, et al

prolonged analgesic effect than GA after operation. The average bed rest time was significantly shorter in the TEA group than in the GA group. Overall satisfaction scores were significantly higher in the TEA group than in the GA group. Side effects were observed at a higher frequency in the GA group than in the TEA group. TEA provided better postoperative pain relief and recovery and lower cost than GA for MRM surgery ${ }^{12}$.

In our preliminary study we analyze 12 patients who had breast cancer operation under TEA technique.

\section{CONCLUSION}

This study demonstrates that the TEA is a useful, safe, and reliable anesthetic technique in breast cancer surgery. It provides excellent anesthetic and surgical conditions, postoperative analgesia, early patient mobilization as well as oral intake, and reduced postoperative morbidity and hospital stay decreased blood loss. So TEA may be an alternative choice to GA especially for the patients with comorbidities who undergo to the oncologic breast surgeries. Further studies are needed with a large number of cases to evaluate the exact indications of the anesthesia choices.

\section{REFERENCES}

1. Sundarathiti $P$, Pasutharnchat $K$, Kongdan $Y$, Suranutkarin PE. Thoracic epidural anesthesia (TEA) with $0.2 \%$ ropivacaine in combination with ipsilateral brachial plexus block (BPB) for modified radical mastectomy (MRM). J Med Assoc Thai. 2005;88(4):513-20.

2. Yektaş A, Ülger GÜ, Çömlekçi $M$, et al. A case of combined thoracic epidural anesthesia-interscalene block application in high-risk mastectomy patients: a case report. Agri. 2014;26(1):39-42.

3. Singh AP, Tewari M. Singh DK, Shukla HS. Cervical epidural anesthesia: A safe alternative to general anesthesia for patients undergoing cancer breast surgery. World J Surg. 2006;30(11):2043-7. 
Non-intubated thoracic epidural anesthesia for modified radical mastectomy as an alternative to general anaesthesia

Sağıroğlu $G$, et al

4. Wijeysundera DN, Beattie WS, Austin PC, Hux JE, Laupacis A. Epidural anesthesia and survival after intermediate-to-high risk non-cardiac surgery: apopulationbased cohort study. Lancet. 2008;372(9638):562-9.

5. Charlson ME, Pompei $P$, Ales KL, Mackenzie CR. A new method of classifying prognostic comorbidity in longitudinal studies: development and validation. J Chronic Dis 1987;40(5):373-83.

6. Wilson E, David A, Mackenzie N, Grant IS. Sedation during spinal anaesthesia: comparison of propofol and midazolam. Br J Anaesth. 1990;64(1):48-52.

7. Guldager $\mathrm{H}$, Kehlet $\mathrm{H}$. Combined epidural-spinal opioid-free anaesthesia and analgesia for hysterectomy. Br J Anaesth. 1999;82:881-5.

8. Doss NW, Ipe J, Crimi T, Rajpal S, Cohen S, Fogler RJ, et al. Continuous thoracic epidural anesthesia with $0.2 \%$ ropivacaine versus general anesthesia for perioperative management of modified radical mastectomy. Anesth Analg. 2001;92(6):1552-7.

9. Oktavia E. A comparative study between thoracic epidural anesthesia and general anesthesia for patients who underwent modified radical mastectomy with axillary lymph node dissection in de la salle university medical center. Indones Biomed J. 2015;7(2):111-6.

10. Hiremath VR. Thoracic epidural anesthesia for modified radical mastectomy-in type 2 diabetes mellitus patient. Journal of Evolution of Medical and Dental Sciences. 2014;3(70):15002-6.

11. Belzarena SD. Comparative study between thoracic epidural block and general anesthesia for oncologic mastectomy. Rev Bras Anestesiol. 2008;58(6):561-8.

12. Yeh CC, Yu JC, Wu CT, Ho ST, Chang TM, Wong CS. Thoracic epidural anesthesia for pain relief and postoperation recovery with modified radical mastectomy. World J Surg. 1999;3(3):256-60. 